\title{
CONSIDERACIONES JURÍDICAS SOBRE LA POLÍTICA AMBIENTAL Y LA PANDEMIA DEL COVID-19
}

\author{
Pierre Foy Valencia \\ Pontificia Universidad Católica del Perú
}

Resumen: El presente estudio identifica algunas premisas, a modo de contexto, sobre la relación ambiente y COVID-19, para luego abordar un aspecto del sistema legal ambiental, es decir la política ambiental y relacionarla con el COVID-19. Para ello, recoge los principios de la política nacional del ambiente y los coteja con ejemplos de transgresión de estos principios en función del COVID-19.

Palabras claves: derecho, política ambiental, gestión ambiental, COVID-19 


\title{
LEGAL CONSIDERATIONS ON ENVIRONMENTAL POLICY AND THE COVID-19 PANDEMIC
}

\begin{abstract}
This study identifies some premises, by way of context, about the relationship between the environment and COVID-19, and then addresses an aspect of the environmental legal system, that is, environmental policy and relates it to COVID-19. National environment and compares them with examples of transgression of these principles based on the COVID-19.
\end{abstract}

Keywords: law, environmental policy, environmental management, COVID-19

\section{Pierre Foy Valencia}

Doctor en Derecho. Máster en Derecho Ambiental (Universidad del País Vasco). Abogado (PUCP). Docente universitario nacional (PUCP, La Molina, entre otros) e internacional. Corresponsal peruano del Centre International de Droit Comparé de l'Environnement (CIDCE). Miembro de la Comisión de Derecho Ambiental de la Unión Internacional para la Conservación de la Naturaleza (UICN). Responsable (asociado) de la división de Derecho y Gestión Ambiental de Baker Tilly, sección Perú. Gerente y socio del Estudio Foy \& Valdez, Consorcio en Derecho Ambiental. Asesor, consultor, investigador en derecho ambiental para instituciones privadas y públicas, nacionales y extranjeras. Promotor del naciente derecho animalístico en el Perú.

Autor de numerosas publicaciones en Derecho Ambiental y animal Publicaciones recientes: Tratado de derecho ambiental: una lectura del derecho ambiental desde la Ley General del Ambiente, (2018), La investigación en el derecho ambiental: hacia una metodología de la investigación para la disertación jurídica ambiental (MIJA), (2019), Testimonios sobre el derecho ambiental: egresados PUCP. Centenario de la Facultad de Derecho de la PUCP (1919 - 2019), (2019).

Correo:pfoy@pucp.edu.pe 


\section{Ambiente y COVID-19}

Durante el año 2020, se han elaborado diversas conexiones y aproximaciones entre la cuestión ambiental (extensible al desarrollo sostenible) y el COVID-19, tanto en perspectivas de impactos positivos, como negativos. Para el primer caso se suele aludir en primera línea a la incidencia zoonótica ${ }^{1}$ como consecuencia de la mala gestión o aprovechamiento insostenible de los ecosistemas, lo cual facilita un conjunto de "liberaciones" como la zoonosis ${ }^{2}$ y la subsecuente pandemia. Refiere Gil Mora (2020), citando a la WWF que es esencial «proteger los ecosistemas naturales, conservar las áreas no contaminadas del planeta, combatir el consumo y el tráfico de especies silvestres, reconstruir el equilibrio de los ecosistemas dañados y detener el cambio climático».

En relación con los impactos positivos, se han evidenciado importantes situaciones como la mejora de la calidad del aire, la caída del $\mathrm{CO}_{2}$ o cierta recuperación de espacios de parte de la fauna silvestre, por mencionar algunos (DW 2020)

En realidad, sobre los orígenes del COVID-19 circulan diferentes hipótesis, como las de caracterizarlo como principalmente natural, aunque con base antropogénica (AA.VV. 2020a) ${ }^{3}$ o aquellas que lo consideran propiamente como un producto manufacturado. (Beltramo y Polo: 2020). Sin duda, las nuevas respuestas o patrones de conducta frente a este proceso, también deben ser evaluadas, pues podrían generar emergentes impactos ambientales (vg. las consecuencias en el recargado uso del plástico u otras demandas de servicios y de consumo, debido a la emergencia).

Responder con medidas garantistas y preventivas de orden interdisciplinario, en resguardo del ambiente y la calidad de vida de la población, en un contexto de emergencia sanitaria, resulta impostergable, para lo cual se requieren soluciones concertadas, además de desideologizadas ${ }^{4}$.

\footnotetext{
1 Enfermedad zoonótica: aquella que puede transmitirse entre animales vertebrados y seres humanos.

2 Léase especies, plagas, virus.

«(...) teorías apuntan a una cadena que incluye el consumo de carne de animales silvestres, los cuales son comercializados en mercados cuyas condiciones sanitarias $y$ de inocuidad son bastante dudosas al igual que la procedencia de los especímenes consumidos en gran variedad de platos típicos, no solo en Wuhan (China), epicentro de la pandemia, sino en la mayoría de los países en desarrollo del globo terráqueo». (Tarazona 2020).

4 Tareas que correspondería desarrollarlas a la brevedad.
} 


\section{Derecho y política ambiental en el sistema jurídico peruano}

De manera parecida a lo señalado en el apartado anterior, pero desde el campo del derecho, se han elaborado -durante el año 2020-diversos trabajos que correlacionan el derecho con la pandemia y el COVID-19 (Pistor, Katharina: 2020; AA.VV.: 2020) y en específico con el derecho ambiental se advierte aun poca literatura (Foy: 2020a, 2020, b, y 2020 c).

Ahora bien, el sistema jurídico ambiental en relación con los riesgos y desastres (Foy 2017a, 2017 b), se ha forjado progresivamente, habiendo generado normas y aplicaciones para determinadas situaciones de emergencia, tanto ambiental cono sanitaria, sin embargo, frente a las dimensiones globales y sus expresiones y desafíos locales, que ha representado la pandemia del COVID-19, se ha podido apreciar muchas de sus carencias o insuficiencias y sobre todo, ineficiencias.

Del conjunto de componentes del sistema jurídico ambiental peruano ${ }^{5} \mathrm{y}$ para efectos del presente -y breve- estudio, interesa enfatizar lo relacionado con las políticas ambientales desde la perspectiva del derecho ${ }^{6}$. En nuestro sistema legal, la política nacional del ambiente (PNA) -derivada del mandato constitucionalrefiere mediante la Ley General del Ambiente: «Artículo 8.- De la Política Nacional del Ambiente 8.1 La Política Nacional del Ambiente constituye el conjunto de lineamientos, objetivos, estrategias, metas, programas e instrumentos de carácter público, que tiene como propósito definir y orientar el accionar de las entidades del Gobierno Nacional, regional y local, y del sector privado y de la sociedad civil, en materia ambiental». Complementariamente en el Reglamento que dicta esta PNA, se presenta como «los objetivos prioritarios, lineamientos, contenidos principales y estándares nacionales de obligatorio cumplimiento. Conforma la política general de gobierno en materia ambiental, la cual enmarca las políticas sectoriales, regionales y locales» (Perú 2009: 3).

En ese sentido, partiendo del referido mandato constitucional (Artículo $67)^{7}$, de la Ley General del Ambiente, (Ley $\mathrm{N}^{\circ} 288611^{8}$ ) y en especial de la Política Nacional del Ambiente (D.S N 12 - 2009 - MINAM), se derivan:

- Políticas ambientales nacionales sectoriales, regionales y locales. Por ejemplo, la política ambiental en materia agrarias, de salud o de educación ambiental.

\footnotetext{
5 Léase, principios, políticas, derechos y obligaciones (vg. instrumentos de gestión) según destinatarios, autoridades e instituciones de gestión, procedimientos, sanciones, entre otros.

6 Pues evidentemente las políticas tienen una dimensión jurídica, pero asimismo conllevan otros enfoques como el propiamente político, tecnológico, de gestión, entre otros.

7 Artículo 67. Política Ambiental. El Estado determina la política nacional del ambiente. Promueve el uso sostenible de sus recursos naturales.

8 Un análisis exhaustivo de esta ley contextualizado con el derecho ambiental como disciplina, puede hallarse en el tratado ras en el Tratado de derecho ambiental peruano. Una lectura del derecho ambiental desde la Ley General del Ambiente (Foy 2018).
} 
- Políticas públicas que insertan la dimensión ambiental. Por ejemplo, las políticas de transporte, minería o pesquería.

- Diversos instrumentos o herramientas que coadyuvan a la implementación y ejecución de estas políticas: es el caso de estrategias, agendas, planes programas, por citar algunos.

- Alcances de políticas internacionales derivados de los compromisos jurídicos suscritos por el Estado peruano.

Al respecto, resulta interesante el Reglamento que regula las Políticas Nacionales (Decreto Supremo $\mathrm{N}^{\circ}$ 029-2018-PCM), mediante la cual -entre otros alcances- se diferencian políticas de estado y políticas de gobierno, vinculación de las políticas nacionales con el SINAPLAN (Artículo 11), así como se fija el contenido de una política nacional ${ }^{9}$.

Cabe precisar que en nuestro sistema legal se ha concebido como instrumentos de gestión ambiental a aquellos «(...) mecanismos orientados a la ejecución de la política ambiental, sobre la base de los principios establecidos en la presente Ley, y en lo señalado en sus normas complementarias y reglamentarias.» (Artículo 16 de la Ley General del Ambiente). No dice expresamente que estos instrumentos sean propiamente los de las políticas ambientales. Tampoco hay otra mención legal que precise de manera diferenciada el concepto de instrumentos de políticas ambientales, anotando que en otros sistemas legales suelen ser equivalentes.

A partir de esta plataforma o base legal de las políticas ambientales en el Perú, se debe desarrollar un análisis situacional y una prospectiva (Mera 2014) en relación con el escenario pos pandémico COVID-19. Tarea que sin duda no es un asunto sólo jurídico, sino un enfoque interdisciplinario, en el cual sin embargo, tampoco puede estar ausente dicha dimensión.

\section{Alcances jurídicos de política ambiental en relación con el COVID-19}

Un ejercicio -un tanto aleatorio no sistemático ni muestral- pareciera relevante para pulsear situaciones ejemplificativas de cómo los principios previstos en la PNA son desetimados y transgredidos (más de lo que ya acontece en escenarios "normalizados"), en relación con el COVID-19 y la pandemia.

\footnotetext{
9 Anexo 1. Contenido de una política nacional: 1. Antecedentes (Presentación, base legal, metodología, diagnóstico, políticas relacionadas. 2. objetivos prioritarios.3. Lineamientos. 4. Estándares nacionales de cumplimiento. 5. La provisión de servicios que deben ser alcanzados y supervisados para asegurar el normal desarrollo de las actividades públicas y privadas (según corresponda). 6. Seguimiento y evaluación. 7. Glosario y acrónimos (según corresponda). 8. Anexo(s) (según corresponda). 9. Bibliografía.
} 


\begin{tabular}{|c|c|}
\hline $\begin{array}{l}\text { Principios } \\
\text { vulnerados }\end{array}$ & Ejemplificación de relación con la cuestión COVID-19 \\
\hline 1. Transectorialidad & $\begin{array}{l}\text { La ausencia de controles legales y fiscalización -desde las diferentes } \\
\text { agencias del Estado- ha dejado vulnerable a los ecosistemas, frente } \\
\text { a prácticas -legales e ilegales- extractivas, transformativas o de } \\
\text { transporte, con mayor intensidad de lo que ya acontece desde la anomia } \\
\text { y disfuncionalidad de los sistemas de control. }\end{array}$ \\
\hline $\begin{array}{l}\text { 2. Análisis costo - } \\
\text { beneficio }\end{array}$ & $\begin{array}{l}\text { No se han analizado ni tomado las medidas adecuadas para que } \\
\text { lo invertido en acciones públicas de prevención y respuestas a la } \\
\text { emergencia sanitaria consideren, en la medida razonable de las } \\
\text { circunstancias, los retornos económicos o ambientales esperables. Por } \\
\text { ejemplo, la reducción o limitación indiscriminada de ciertos rubros de } \\
\text { las actividades económicas, ha presionado a poblaciones y negocios a } \\
\text { transgredir -más aún-la protección de valores ambientales precisamente } \\
\text { por el estado de necesidad. En consecuencia, la indispensable inmediatez } \\
\text { y aplicación de costos que requerían las medidas sanitarias, han debido } \\
\text { ponderarse para evitar riesgos ambientales a escalas diferentes escalas } \\
\text { de actuación de personas, grupos e instituciones (públicas y privadas), } \\
\text { pequeños, medianas y grandes. }\end{array}$ \\
\hline 3. Competitividad & $\begin{array}{l}\text { La inexistencia de un enfoque estratégico y progresivo para responder } \\
\text { a los requerimientos de la producción y las actividades económicas } \\
\text { en relación con las medidas de prevención sobre la pandemia, redujo } \\
\text { este principio que ciertamente debe ser enfocado con lógica de } \\
\text { sostenibilidad, en el contexto de emergencia. En consecuencia, la } \\
\text { competitividad y transparencia en la misma se torna incierta y la calidad } \\
\text { ambiental tiende a reducirse en esta lucha por sobrevivencia de los } \\
\text { negocios, dejando en segundo o tercer plano, la seguridad ambiental. }\end{array}$ \\
\hline $\begin{array}{l}\text { 4. Cooperación } \\
\text { público-privada }\end{array}$ & $\begin{array}{l}\text { Se ha asistido a una lamentable desconexión de este principio durante la } \\
\text { emergencia sanitaria, puesto que muchos segmentos del sector privado } \\
\text { (empresas, colectivos comunales o poblacionales) tomaron la delantera, } \\
\text { a contrapelo de la inacción o ineficiencia del Estado. } \\
\text { En esa misma tendencia, desde el sector privado y social, se ha debido } \\
\text { continuar con la línea de solidaridad y empatía con el ambiente, en ese } \\
\text { contexto de emergencia sanitaria. }\end{array}$ \\
\hline 5. Mejora continua & $\begin{array}{l}\text { El deterioro continuo es precisamente -y no este principio de la mejora } \\
\text { continua- el que ha primado en este contexto de emergencia sanitaria, } \\
\text { en relación con la prevención y la seguridad ambiental, amenazando con } \\
\text { ella la sostenibilidad ambiental a largo plazo. }\end{array}$ \\
\hline $\begin{array}{l}\text { 6. Gestión por } \\
\text { resultados }\end{array}$ & $\begin{array}{l}\text { Las acciones públicas, en el contexto de la emergencia sanitara y la } \\
\text { pandemia no se orientaron hacia una gestión por resultados, debido al } \\
\text { desconcierto y garete gubernamental, a partir de lo cual lo ambiental no } \\
\text { fue relevantemente internalizado en la práctica. Por lo tanto, resultaba } \\
\text { inimaginable- y así quedó demostrado en los hechos- cualquier } \\
\text { referente a incentivos y sanciones en función a las buenas o malas } \\
\text { prácticas ambientales. }\end{array}$ \\
\hline 7. Seguridad jurídica & $\begin{array}{l}\text { La "normorrea" multisectorial de la emergencia, derivó en un enorme } \\
\text { desconcierto normativo y de disposiciones oscilantes, en cuyo contexto } \\
\text { se apreciaba una inseguridad jurídica. Esto, ciertamente repercutía en } \\
\text { la normativa ambiental de los recursos naturales y de las actividades } \\
\text { sectoriales, que por mandato legal, deben ser de carácter sostenible. }\end{array}$ \\
\hline
\end{tabular}

Elaborado por el autor. 
Como se puede colegir de este ejercicio aproximativo, si bien es cierto que contando con elementos rectores de una política ambiental -expresada mediante sus principios y subsecuentes mandatos legales- no se seguían con la rigurosidad que ameritaba, peor aún en el contexto de la emergencia sanitaria y el relajo de los controles institucionales y de las conductas de las personas.

\section{Consideraciones finales a modo de conclusiones}

- $\quad$ En lenguaje jurídico, las fuentes materiales para una aproximación legal ambiental en relación con el COVID-19, sin duda están referidas a las correlaciones e impactos ambientales con ese virus, así como de su secuela pandémica.

- Una perspectiva sistémica desde el derecho ambiental respecto el COVID-19, supone correlacionarlo con los diferentes componentes del sistema jurídico ambiental. Sin embargo, para el presente estudio, se ha elegido el componente de la política ambiental.

- La política ambiental y toda la estela de instrumentos que se le desprenden, tiene un conjunto de principios que son genéricamente válidos para las políticas modernas, sólo que aterrizados en lo ambiental.

- Cabe acotar que las políticas ambientales a su vez son tributarias de unos marcos de política mayor, a la cual se deben y con las que se interrelacionan de manera inextricable.

- A partir del proceso pandémico del COVID-19, en el caso del Perú, se ha podido apreciar muestralmente, cómo los principios de la política nacional del ambiente (PNA), han sido sobrepasados, más allá de la transgresión en épocas de "normalidad".

- Si bien no ha sido materia del presente trabajo desarrollar una prospectiva sobre la pospandemia y el sistema jurídico ambiental, queda como una tarea cercana y con aproximación interdisciplinaria, recogiendo la experiencia acontecida. 


\section{Referencias}

AA.VV. (2020). Derecho de los Desastres: Covid-19. 2 tomos. Lima, Fondo Editorial de la PUCP.

AA. VV. (2020a). Sopa de Wuhan. Editorial: ASPO (Aislamiento Social Preventivo y Obligatorio). Recuperado de: http://iips.usac.edu.gt/wp-content/ uploads/2020/03/Sopa-de-Wuhan-ASPO.pdf

Beltramo, Carlos y Polo Carlos (2020). Pandemonium ¿De la pandemia al control total?

1era. edición: Mayo 2020. Recuperado de:

https://www.cafeviena.pe/wp-content/uploads/2020/05/PandemoniumDe-la-pandemia-al-control-total.pdf

Deutsche Welle DW. (2020). Siete cambios ambientales que provocará el coronavirus.

Recuperado de: https://www.dw.com/es/siete-cambios-ambientales-queprovocar\%C3\%A1-el-coronavirus/g-53096981

Foy, Pierre

2017a Sobre desastres y emergencias ambientales. A propósito del artículo 28 de la Ley General del Ambiente (II). Revista Actualidad Gubernamental, año XIII, N 107, pp. XIII-1 / XIII-1.

2017b Sobre desastres y emergencias ambientales. A propósito del artículo 28 de General del Ambiente (I). Revista Actualidad Gubernamental, año IX, N ${ }^{\circ}$ 106, pp. XIII-1 / XIII-3.

2018a Tratado de derecho ambiental peruano. Una lectura del derecho ambiental desde la Ley General del Ambiente. 2 volúmenes. Lima: Instituto Pacífico.

2020a Sistema jurídico ambiental, derecho de los desastres y Covid-19. En AA.VV. Derecho de los Desastres: Covid-19. Lima, Fondo Editorial de la PUCP, p.639 $-661$

2020b Instrumentos de gestión ambiental, emergencias ambientales y covd19” (inédito).

Revista del Departamento de sociología rural de la Facultad de economía y planificación de la Universidad Nacional Agraria La Molina. Lima.

2020c El derecho ambiental y de protección animal en el contexto de la emergencia sanitaria Covid-19 (inédito). Instituto de Derechos Humanos y Desarrollo de la Universidad de San Martín de Porres: Revista virtual: Derechos Humanos en el Contexto de la Emergencia Sanitaria COVID 19. Lima.

Gil Mora, Juan (2020). Repercusiones ambientales de la pandemia COVID-19. CENTRO CULTURAL SAN FRANCISCO SOLANO. Recuperado de: http://www. centroculturalsol.com/COVID-19-Repercusiones\%20ambientales.pdf

Gómez Durán, T. (2020). ¿Por qué la deforestación y la pérdida de especies abren la puerta a nuevas enfermedades?. Recuperado de: https:// es.mongabay.com/2020/04/Covid-19-deforestacion-y-la-perdida-deespecies/ 
Mera Rodríguez, Carlos (2014). Pensamiento prospectivo: visión sistémica de la construcción del futuro Análisis. Revista Colombiana de Humanidades, vol. 46, núm. 84, enero-junio, 2014, pp. 89-104 Universidad Santo Tomás Bogotá, Colombia, Recuperado de: https://www.redalyc.org/ pdf/5155/515551535005.pdf

MINAM (2009). Política Nacionaldel ambiente. Decreto Supremo № 012-2009-MINAM de 23 de Mayo de 2009, Lima.

Pistor, Katharina (2020). Law in the Time of COVID-19. Books. 240.

Recuperado de: https://scholarship.law.columbia.edu/books/240

Tarazona, Ariel (2020). Relaciones en tiempos de pandemia: COVID-19 y bienestar animal, ambiental y humano. Revista Facultad Nacional de Agronomía Medellín, 73(2), 9128-9130. Retrieved October 12, 2020, Recuperado de: http://www.scielo.org.co/scielo.php?script=sci_arttext\&pid=S030428472020000209128\&lng=en\&tlng=es

UICN (2020). Declaración de la UICN sobre la pandemia de COVID-19. Recuperado de: https://www.iucn.org/es/news/secretaria/202004/declaracion-de-lauicn-sobre-la-pandemia-de-Covid-19 